\title{
Study on IMO New Requirement: Ship Fuel Oil Consumption Data Collection and Reporting
}

\author{
Wang Deling ", Chen Yuli, Huang Changhai, Chen Liang, Wu Changyue \\ Merchant Marine College, Shanghai Maritime University, Shanghai, China \\ Email address: \\ dlwang@shmtu.edu.cn (Wang Deling), ylchen@shmtu.edu.cn (Chen Yuli),chhuang@shmtu.edu.cn (Huang Changhai), \\ chenliang@shmtu.edu.cn (Chen Liang), cywu@shmtu.edu.cn (Wu Changyue) \\ ${ }^{*}$ Corresponding author
}

\section{To cite this article:}

Wang Deling, Chen Yuli, Huang Changhai, Chen Liang, Wu Changyue. Study on IMO New Requirement: Ship Fuel Oil Consumption Data Collection and Reporting. American Journal of Water Science and Engineering. Vol. 6, No. 1, 2020, pp. 50-59.

doi: 10.11648/j.ajwse.20200601.16

Received: January 23, 2020; Accepted: February 19, 2020; Published: March 24, 2020

\begin{abstract}
The increase of heat in the Earth's atmosphere caused by greenhouse gases emissions has changed the natural climate variability, resulting in the climate change. According to the Third IMO GHG Study 2014, international shipping has emitted 866 million tonnes of GHG per year on average between 2007 and 2012 which represented approximately $2.4 \%$ of global GHG emissions. In order to mandatorily implement the ship fuel consumption data collection and reporting scheme, IMO adopted amendments to MARPOL Annex VI on data collection system for fuel oil consumption of ships by the resolution MEPC.278 (70), in which a new "Regulation 22A-Collection and reporting of ship fuel oil consumption data" was added, requiring that each ship of 5,000 gross tonnage and above, from calendar year 2019, shall collect the fuel consumption data as specified and report to its flag state. In order to implement properly the new regulations, this paper, supported by "a pilot project of shipboard fuel consumption data collection", systematically analyses the IMO requirements for ship fuel consumption data collections and data collection methods. And based on the shipboard real practices and experiences, the whole process of data collection is demonstrated, and precautions and suggestions for more accurate data collection are also provided, for the easy reference by parties concerned such as ship masters, ship owners, managers, maritime authorities, etc.
\end{abstract}

Keywords: Greenhouse Gases, Climate Change, Ship Fuel Consumption, Data Collection, MARPOL Annex VI

\section{Introduction}

Human activities, in particular the rising fossil fuel combustion, have directly emitted growing amounts of greenhouse gases (GHG) into the Earth's atmosphere. A cumulative rise of anthropogenic GHG such as carbon dioxide (CO2), methane (CH4) and nitrous oxide (N2O) has led to in the Earth's atmosphere a rise of the heat from the sun that would in principle be rebounded back into space. [1] The increase of heat in the Earth's atmosphere has changed the natural climate variability, resulting in the climate change. The direct impacts of climate change on the Earth can be summarized as follows:

1) Increases in the average global temperature (global warming);

2) Changes in cloud cover and precipitation particularly over land;
3) Melting of ice caps and glaciers and reduced snow cover, and

4) Increases in ocean temperatures and ocean acidity.

Further, it is well recognized that the major threats caused by the global warming have had severe impacts on human sustainable survival and natural systems, including:

1) The rise of the sea mean level,

2) The biodiversity losses,

3) More frequent and extreme weather events,

4) The creation of new diseases,

5) The famine aggravation, and

6) The losses of traditional lifestyles.

International shipping carries over $80 \%$ of all traded goods by volume and over $70 \%$ by value. About more than 50,000 merchant ships registered in over 150 nations are trading internationally. According to the Third IMO GHG Study 2014, international shipping has emitted 866 million tonnes of GHG 
(in $\mathrm{CO}_{2}$ equivalent) per year on average between 2007 and 2012 which represented approximately $2.4 \%$ of global anthropogenic GHG emissions, and emitted 846 million tonnes of $\mathrm{CO}_{2}$ emissions per year on average between 2007 and 2012, accounting for about $2.6 \%$ of global $\mathrm{CO}_{2}$ emissions per year on average on the same period. Moreover, despite the amelioration through the technological and operational measures, the future $\mathrm{CO}_{2}$ emissions from the international shipping sector are projected to rise by between $50 \%$ and $250 \%$ over the period 2012-2050 based on the business-as-usual (BAU) scenario that assumes a tripling in world trade [2].

Consequently, it is indispensable that the international shipping industry shall take necessary actions to effectively limit and reduce the GHG emissions from ships in order to help achieve the goal in controlling the rise of global surface temperature which is laid down in the Paris Agreement to The United Nations Framework Convention on Climate Change (UNFCCC).

IMO has been always dedicating itself in GHG emission reduction in shipping sector. A variety of regulations has been adopted by IMO to increase the energy efficiency in shipping field, thus reducing the GHG emissions. In order to mandatorily implement the ship fuel consumption data collection and reporting scheme, IMO adopted amendments to MARPOL Annex VI on data collection system for fuel oil consumption of ships through the resolution MEPC.278 (70), which entered into force on 1 March 2018. [3] A new "Regulation 22A-Collection and reporting of ship fuel oil consumption data" was added after existing regulation 22, MARPOL 73/78 Annex VI chapter 4, requiring that "each ship of 5,000 gross tonnage and above, from calendar year 2019, shall collect the data specified in appendix IX to the Annex, for that and each subsequent calendar year or portion thereof, as appropriate, according to the methodology included in the SEEMP." [4]

However, to collect and report various fuel consumption data as regulated by the newly added regulation is never a easy process. Supported by "a pilot project of shipboard fuel consumption data collection", this paper systematically analyses the IMO requirements for ship fuel consumption data collections and data collection methods. And based on the shipboard real practices and experiences, the whole process of data collection is demonstrated, and precautions and suggestions for more accurate data collection are also provided, for the easy reference by parties concerned such as ship masters, ship owners, managers, maritime authorities, etc..

\section{Ship Fuel Oil Consumption Data Collection and Reporting}

\subsection{Intent of Ship Fuel Consumption Data Collection and Reporting}

The annual accurate amount of $\mathrm{CO}_{2}$ emissions from ships is one of the most important bases for the international shipping sector to scientifically develop the strategy of reducing the GHG emissions from ships, assess the implementation effectiveness of current mandatory regulations and introduce new mandatory regulations. The amount of $\mathrm{CO}_{2}$ emissions from a ship is able to be calculated based on the multiplication between ship's fuel consumption and fuel emission factor:

Amount of $\mathrm{CO}_{2}$ emission=ship's fuel consumption $\times$ fuel emission factor

As the fuel emission factor of $\mathrm{CO}_{2}$ varies from different types of fuel, the annual accurate amount of various types of ships' fuel consumption shall be firstly obtained before the annual accurate amount of $\mathrm{CO}_{2}$ emissions from ships is calculated. However, due to the fact that ships engaged in international voyages are of great amounts, a great variety, complicated operational modes and high mobility, the traditional estimation approaches based on the global marine fuel sales, statistics analysis of global ship fleet database as well as statistics analysis of global ship navigational status are not the most accurate methods to calculate the annual cumulative amount of $\mathrm{CO}_{2}$ emissions from ships. [5]

In reality, it is a common practice that each ship records daily fuel consumption data and reports this data to the relevant parties such as its managers and charterers. Therefore, if it is mandatorily required that each ship record and report its annual fuel consumption data to its flag state and the flag state accordingly submit the data collected from each ship to the IMO, then in principle the total amount of annual fuel consumption from ships can be determined by the IMO and thus the total amount of annual $\mathrm{CO}_{2}$ emissions from ships can also be calculated.

\subsection{IMO Mandatory Requirements on Ship Fuel Consumption Data Collection and Reporting}

In order to mandatorily implement the ship fuel consumption data collection and reporting scheme, IMO adopted amendments to MARPOL Annex VI on data collection system for fuel oil consumption of ships through the resolution MEPC.278 (70), which entered into force on 1 March 2018. Under the amendments, the regulation 22A of collection and reporting of ship fuel oil consumption data, the Appendix IX on information to be submitted to the IMO Ship Fuel Oil Consumption Database and the Appendix X on Form of Statement of Compliance - Fuel Oil Consumption Reporting are added in the chapter 4 of MARPOL Annex VI. [6]

The amendments require ships of 5,000 gross tonnage and above shall to collect consumption data for each type of fuel oil they use, as well as other, additional, specified data including proxies for transport work. The aggregated data shall be reported to the flag State after the end of each calendar year (the first calendar year begins from 1 January until 31 December inclusive 2019 within 3 months after the end of each calendar year) and the flag State, having determined that the data has been reported in accordance with the requirements, issues a Statement of Compliance to the ship no later than 5 months from the beginning of the calendar year. 
Flag States are required to subsequently transfer this data to an IMO Ship Fuel Oil Consumption Database. IMO will be required to produce an annual report to $\mathrm{MEPC}$, summarizing the data collected. Before the process, on or before 31 December 2018, in the case of a ship of 5,000 gross tonnage and above, the SEEMP in its Part II shall include a description of the methodology that is used to collect the data and the processes that are used to report the data to the ship's flag State.

Requirements of ship fuel consumption data collection and reporting are a multi-parties process in which ships, flag States, Recognized Organizations (RO) and IMO Secretariat are technically involved. In terms of the developing progress of global ship information system, it directly requires IMO to develop and maintain a new Database on global Ship Fuel Consumption Data. [7] To make it more clear, the whole process and corresponding descriptions on ship fuel consumption data collection are summarized in Figure 1. And Figure 2 shows the regulatory timeline of ship fuel oil data collection (with the year of 2019 as an example).

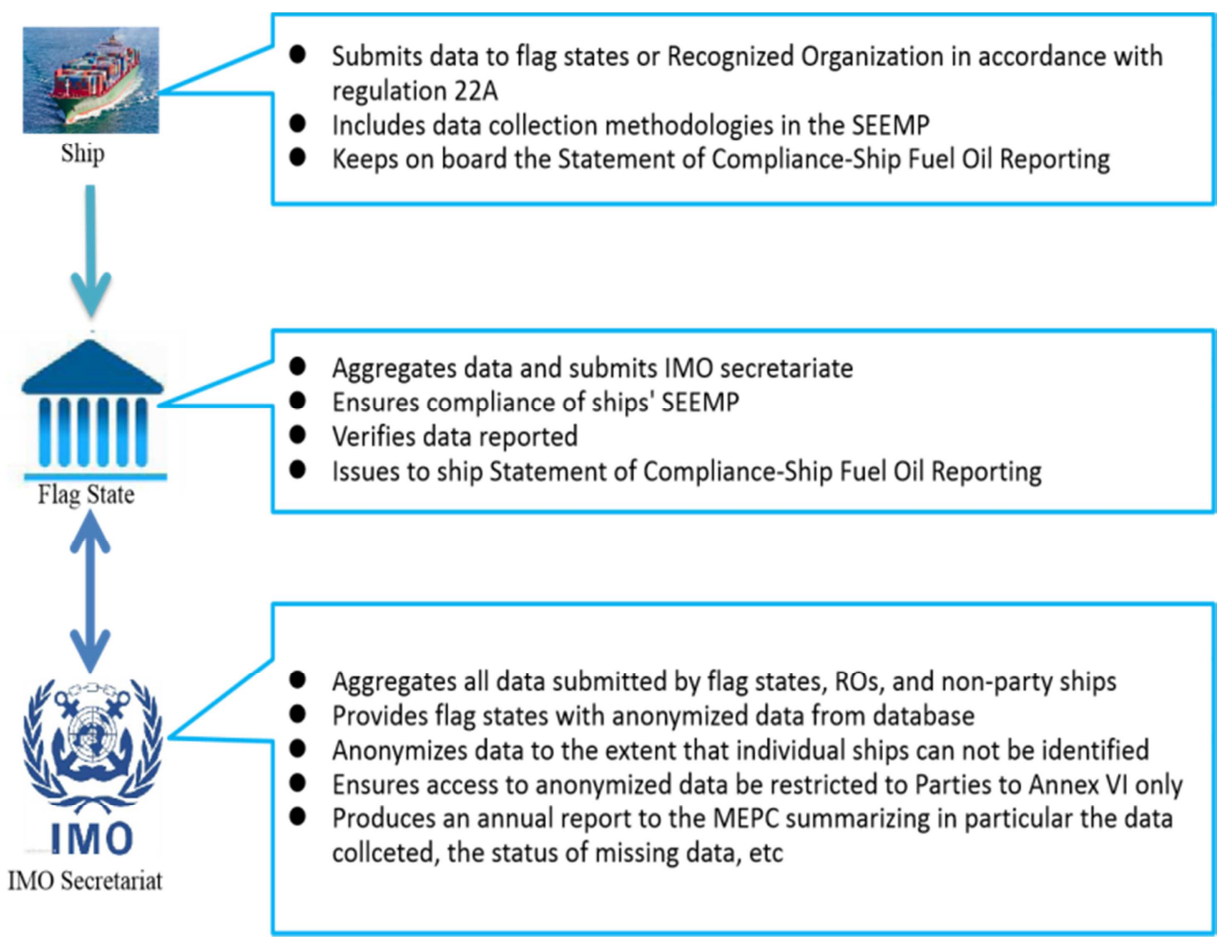

Figure 1. Process of ship fuel consumption data collection and reporting.

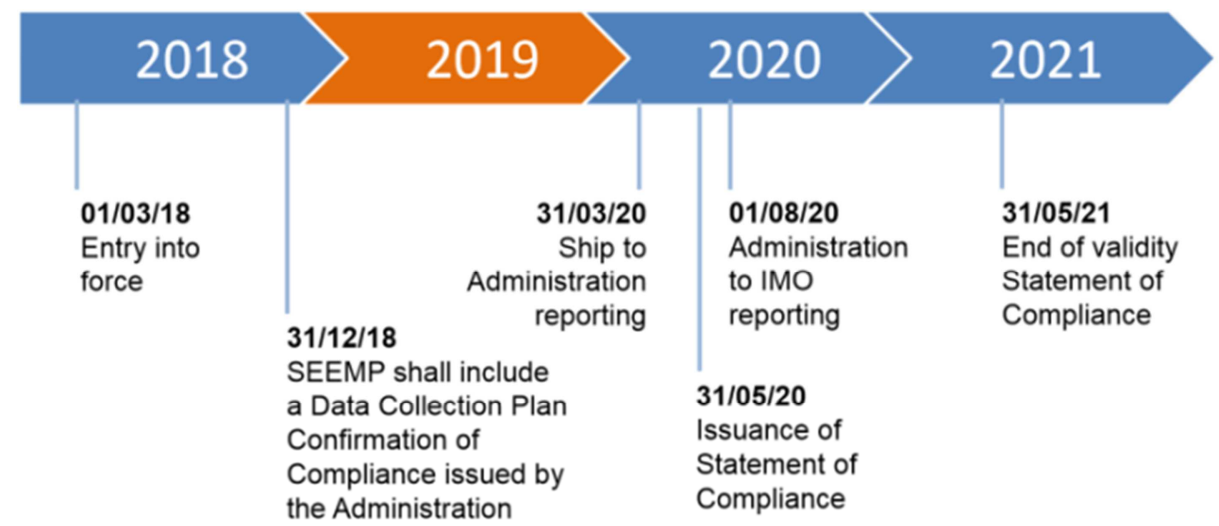

Figure 2. Regulatory timeline of ship fuel oil data collection.

\subsection{Ship Fuel Emission Factor}

Fuel emission factor is a non-dimensional conversion factor representing the relation between fuel consumption and its corresponding gas emissions. The emission factor of
$\mathrm{CO} 2$ for various types of fuel oil (CF) can be found in the 2018 Guidelines on the method of calculation of the attained EEDI for new ships (Resolution MEPC.308 (73)), [8] see Table 1. 
Table 1. Emission factor of $\mathrm{CO} 2$ for various types of fuel oil.

\begin{tabular}{ll}
\hline Fuel oil Type & $\boldsymbol{C F}$ (t-CO $\mathbf{C}_{2} / \mathbf{t}$-Fuel) \\
\hline Diesel/Gas oil (e.g. ISO 8217 grades DMX through DMB) & 3.206 \\
Light fuel oil (LFO) (e.g. ISO 8217 grades RMA through RMD) & 3.151 \\
Heavy fuel oil (HFO) (e.g. ISO 8217 grades RME through RMK) & 3.114 \\
Liquefied petroleum gas (LPG) (Propane) & 3.000 \\
Liquefied petroleum gas (LPG) (Butane) & 3.030 \\
Liquefied natural gas (LNG) & 2.750 \\
Methanol & 1.375 \\
Ethanol & 1.913 \\
Other (........) & \\
\hline
\end{tabular}

\subsection{Data Types of Ship Fuel Consumption Collection and Reporting}

Some of the data reported by ships to IMO as required, such as IMO number, ship type, tonnage, will not generally change unless the ship concerned changes her class, flag state or owner, while some of the data such as distance travelled, hours underway, will vary over time and place. [9] Hence, data related to collection and reporting of ship fuel oil consumption data are divided by this paper into two types, static data (ship basic data) and dynamic data.

1) Ship static data
In accordance with the appendix IX of MARPOL Annex VI and to the 2016 Guidelines for the development of a SEEMP (resolution MEPC.282 (70)), in particular its appendix 3, the contents and requirements of the 8 types of ship static data to be recorded during the implementation of the ship fuel oil consumption data collection and reporting are shown in le 2. [10]

2) Ship dynamic data

The contents and requirements of the 6 types of ship dynamic data to be recorded during the implementation of the ship fuel oil consumption data collection and reporting are shown in Table 3.

Table 2. Static data reporting format for the data collection system.

\begin{tabular}{|c|c|c|}
\hline No. & Ship static data & Requirement \\
\hline 1 & IMO number & In accordance with the IMO Ship Identification Number Scheme, adopted by the Organization by resolution A.1078 (28). [11] \\
\hline 2 & Ship type & As defined in regulation 2 of MARPOL Annex VI or other. \\
\hline 3 & Gross tonnage & Gross tonnage should be calculated in accordance with the International Convention on Tonnage Measurement of Ships, 1969. \\
\hline 4 & Net tonnage & $\begin{array}{l}\text { NT should be calculated in accordance with the International Convention on Tonnage Measurement of Ships, 1969. If not } \\
\text { applicable, note "N/A". }\end{array}$ \\
\hline 5 & DWT & $\begin{array}{l}\text { DWT means the difference in tonnes between the displacement of a ship in water of the relative density of } 1025 \mathrm{~kg} / \mathrm{m} 3 \mathrm{at} \text { the } \\
\text { summer load draught and the lightweight of the ship. The summer load draught should be taken as the maximum summer } \\
\text { draught as certified in the stability booklet approved by the Administration or an organization recognized by it. }\end{array}$ \\
\hline 6 & $\begin{array}{l}\text { EEDI (if } \\
\text { applicable) }\end{array}$ & $\begin{array}{l}\text { EEDI should be calculated in accordance with the the appendix IX of MARPOL Annex VI and to the } 2016 \text { Guidelines for the } \\
\text { development of a SEEMP (resolution MEPC. } 282(70) \text { ), in particular its appendix 3. If not applicable, note "N/A". }\end{array}$ \\
\hline 7 & $\begin{array}{l}\text { Ice class (if } \\
\text { applicable) }\end{array}$ & $\begin{array}{l}\text { Ice class should be consistent with the definition set out in the International Code for ships operating in polar waters (Polar } \\
\text { Code), adopted by resolutions MEPC. } 264 \text { (68) and MSC.385 (94)). If not applicable, note "N/A". }\end{array}$ \\
\hline 8 & $\begin{array}{l}\text { Power output } \\
\text { (rated power) } \\
(\mathrm{kW})\end{array}$ & $\begin{array}{ll}\text { Main Propulsion Power } & \begin{array}{l}\text { Power output (rated power) of main and auxiliary reciprocating internal combustion engines } \\
\text { over } 130 \mathrm{~kW} \text { (to be stated in } \mathrm{kW} \text { ). Rated power means the maximum continuous rated power as } \\
\text { specified on the nameplate of the engine. }\end{array}\end{array}$ \\
\hline
\end{tabular}

Table 3. Dynamic data reporting format for the data collection system.

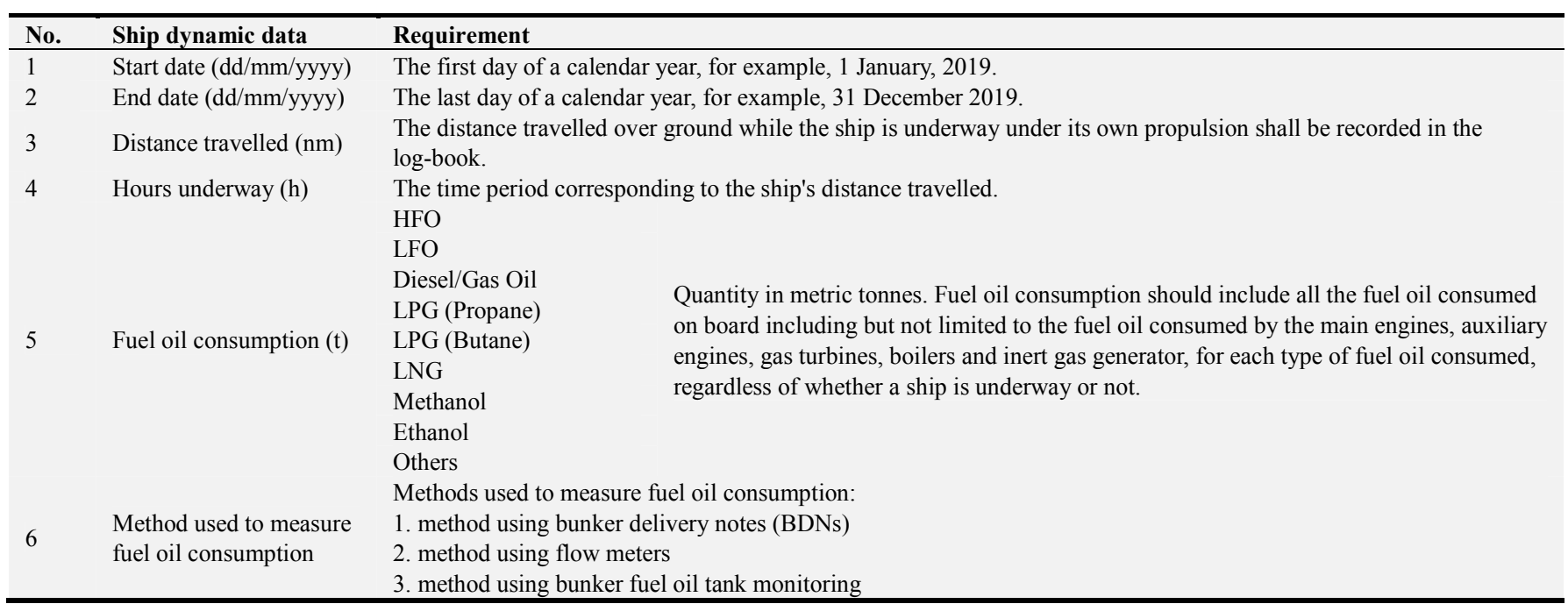




\section{Analysis on Methods of SHIP Fuel Consumption Data Collection}

In compliance with the 2016 Guidelines for the development of a SEEMP (resolution MEPC.282 (70)), in particular Part II - data collection plan, the Data collection plan shall include a description of the methodology that will be used to collect ship fuel oil data. Presently, there are three methods recognized by IMO for collecting fuel consumption data as is shown in Tables 2-3 above. [12]

\subsection{Method Using Bunker Delivery Notes (BDNs)}

\subsubsection{Method Analysis}

According to Regulation 18 of MARPOL Annex VI, vessels of $400 \mathrm{GT}$ and above as well as platforms and drilling rigs shall keep the bunker delivery notes (BDNs) on board for a period of not less than three years following the delivery. The BDN is issued by the ship and the bunker fuel suppliers. The BDN has to contain at least the information specified in Appendix V of MARPOL Annex VI, e.g. date and time of commencement of delivery, name of marine fuel oil supplier, oil type, temperature, density, viscosity, quantity, etc. [3]

Annual fuel oil consumption is the total mass of fuel oil used on board the vessel as reflected in the BDNs. In this method, the fuel oil quantities recorded in the BDNs can be used to determine the annual total amount of fuel oil consumption, plus the amount of fuel oil left over from the last calendar year period, less the amount of fuel oil carried over to the next calendar year period and less the amount of fuel oil offloaded during the calendar year.

The annual total amount of fuel oil consumption:

$=$ the BDN fuel oil quantities+the amount of fuel oil left over from the last calendar year period

i. the amount of fuel oil carried over to the next calendar year period

ii. the amount of fuel oil offloaded during this calendar year

Where, the amount of fuel oil left over from the last calendar year period and the amount of fuel oil carried over to the next calendar year period can be determined by using bunker fuel oil tank reading on board at the start and end of the cycle.

The method using BDNs is shown in Figure 3.

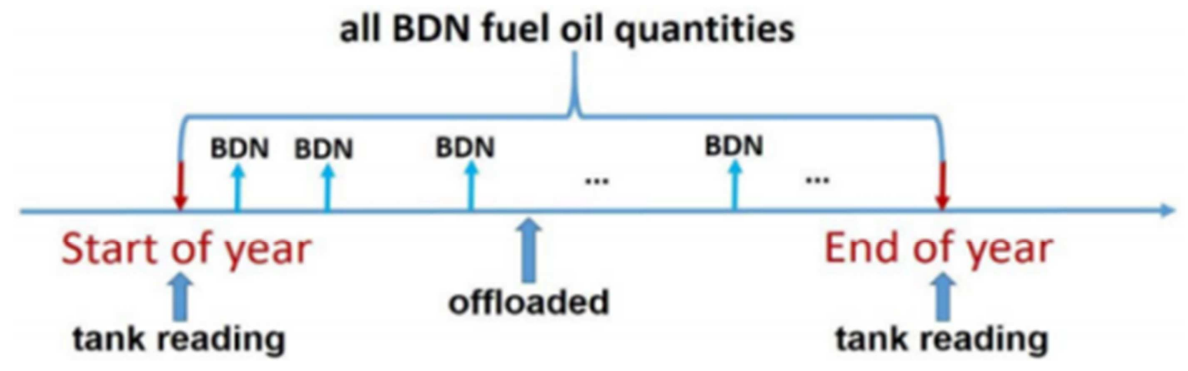

Figure 3. Method using bunker delivery notes.

\subsubsection{Precautions and Suggestions}

The Data Collection Plan should set out how the ship will operationalize the summation of BDN information and conduct tank readings. When using BDN to determine the total fuel oil consumption of a ship in a calendar year, there might be some factors affecting the accuracy of fuel consumption data collected. Therefore, the following precautions and suggestions are given:

1) For voyages that span the data reporting period, stage fuel oil consumption should be performed by means of tank reading at the voyage starting port and using the average number of voyage days.

2) The tank monitoring should be carried out by using appropriate methods and should be clearly defined in the data collection plan.

3) The accuracy of this method mainly depends on the accuracy of the amount of fuel oil recorded on BDNs.

4) The tank monitoring method for determining the remaining tank oil quantity before and after the cycle should be read and calibrated according to the requirements.
5) The annual amount of fuel oil offloaded shall be determined on the basis of the records in the Ship's Oil Record Book.

6) Any supplementary data used for determining tank fuel discrepancies should provide supporting documentary evidence.

7) A summary of annual BDNs shall be provided to flag state on the specified date.

8) This method is not applicable for ships where there are no BDNs on board.

9) If the ship uses shipborne cargo (such as LNG) as fuel, this method cannot be used alone.

\subsubsection{Data Submitted to Flag State by Ship}

The total fuel oil consumption of the vessel for one calendar year can be determined by using the bunker delivery notes. Summary submitted, in appropriate format as required by IMO, to the flag state. To make it more clear, this paper makes a sample table, which includes all the required information, see Table 4. 
Table 4. Sample of the annual collected data summaries by using bunker delivery notes.

\begin{tabular}{|c|c|c|c|c|c|c|c|c|}
\hline \multirow{2}{*}{ Date of Operations (dd/mm/yyyy) } & \multicolumn{7}{|c|}{ Fuel oil type/Mass (t) } & \multirow{2}{*}{ Descriptions } \\
\hline & DO/GO & LFO & HFO & LPG (P) & LPG (B) & LNG & Others & \\
\hline \multicolumn{9}{|l|}{ Bunker delivery notes } \\
\hline 01/01/2019 & & & 150 & & & & & \\
\hline \multicolumn{9}{|l|}{$02 / 01 / 2019$} \\
\hline $12 / 01 / 2019$ & & & 300 & & & & & \\
\hline ......... & & & 0 & & & & & \\
\hline a. Annual Supply Amount & 0 & 0 & 450 & 0 & 0 & 0 & 0 & \\
\hline \multicolumn{9}{|l|}{ Correction for the tank oil remaining } \\
\hline 01/01/2019 & & & 400 & & & & & \\
\hline $31 / 12 / 2019$ & & & -200 & & & & & \\
\hline b. Correction for the tank oil remaining & 0 & 0 & 200 & 0 & 0 & 0 & 0 & \\
\hline \multicolumn{9}{|l|}{ Other corrections } \\
\hline \multicolumn{9}{|l|}{ 03/01/2019 } \\
\hline \multicolumn{9}{|l|}{$15 / 08 / 2019$} \\
\hline c. Annual other corrections & 0 & 0 & 0 & 0 & 0 & 0 & 0 & \\
\hline \multicolumn{9}{|l|}{ Annual fuel oil consumption } \\
\hline Annual Fuel Oil Consumption $(a+b+c)$ & 0 & 0 & 650 & 0 & 0 & 0 & 0 & \\
\hline
\end{tabular}

\subsection{Method Using Bunker Fuel Oil Tank Monitoring on Board}

\subsubsection{Method Analysis}

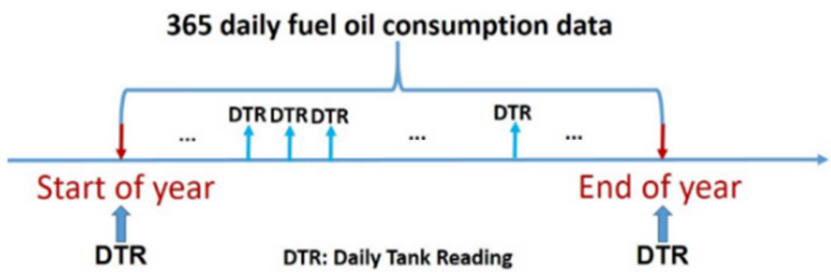

Figure 4. Method using bunker fuel oil tank monitoring on board.

The fuel amount in oil tank is normally measured every day by seafarers to identify and record fuel oil consumption. Therefore, the annual fuel oil consumption on a ship will be identified by calculating all daily records. Method using bunker fuel oil tanker monitoring can be expressed as Figure 4.

The rationale of method using bunker fuel oil tank monitoring is to detect the level of liquid (or ullage) in oil tank through the measurement devices, then the amount of fuel remaining and fuel consumption can be acquired via data conversions and corrections. At present, the means of using bunker fuel oil tank monitoring on ships can be categorized as manual, mechanical and electronic. [13]

\subsubsection{Precautions and Suggestions}

When using the manual tank reading method to measure the fuel consumption of the ship, there might also be some factors affecting the accuracy of fuel consumption data collected. Therefore, The following precautions and suggestions are given:

1) Before measuring, it should be clear whether to take sounding or ullage, and then identify the datum plate and the measurement point.

2) The tape shall be qualified and within the validity period of use.

3) The tape cannot be bent or damaged and connection between tape and weighted bob should not be loosened.

4) The scale of tape should be clearly visible and the minimum division value should be no more than $1 \mathrm{~mm}$.

5) Generally, the 500grams bob is used for the measurement of light oil and 1000-gram bob for crude oil or heavy oil.

6) When measuring light oil, the tape should be raised up and rolled back as long as the bob touches the bottom of the oil tank.

7) When measuring heavy oil, the tape should be raised up and rolled back after the bob touches the bottom of the oil tank for about 5 seconds.

8) When taking sounding, the tape should be rolled inside the oil tank stably so that the bob is able to touch the tank bottom lightly. It should be avoided that the liquid level sloshing caused by heavily rolling the tape inside the oil tank affects the measurement results.

9) When reading, the tape should not be laid flat or inverted in order to prevent the liquid level from rising, and the line of sight should be vertical to the tape. The millimeter value should be read firstly followed by the centimeter, decimeter and meter.

10)If the water mark or oil mark on the tape is not clear, the oil finding paste should be applied at the predicted value position. Then the reading should be based on the discoloration line on the tape.

11)After the measurement is completed, the liquid remaining on the tape should be wiped off with a dry cloth while the tape is being rolled back, and the tape should be completely stowed in its drum.

12) The accuracy of manual measurement is related to such factors as the position of datum plate, measuring tools, conversion tables, ship inclination, etc.

13) Measuring tools should be calibrated and maintained regularly, and records of such calibrations and maintenance should be kept on board ships.

14) The volume measured manually may differ from the actual volume. 
15)Manual tank reading method is not suitable for ships fueled by gas.

\subsubsection{Data Submitted to Flag State by Ship}

When using bunker fuel oil tank monitoring on board to determine the total fuel oil consumption of the vessel for one calendar year, a summary should be submitted, in appropriate format as required by IMO, to the flag state. To make it more clear, this paper makes a sample table, which includes all the required information, see Table 5 .

Table 5. Sample of the annual collected data summaries by using bunker fuel oil tank monitoring on board.

\begin{tabular}{|c|c|c|c|c|c|c|c|c|c|c|}
\hline \multirow{2}{*}{$\begin{array}{l}\text { Date from } \\
\text { (dd/mm/yyyy) }\end{array}$} & \multirow{2}{*}{$\begin{array}{l}\text { Date to } \\
\text { (dd/mm/yyyy) }\end{array}$} & \multirow{2}{*}{$\begin{array}{l}\text { Distance } \\
\text { travelled }(\mathrm{nm})\end{array}$} & \multirow{2}{*}{$\begin{array}{l}\text { Hours underway } \\
\text { (hh: mm) }\end{array}$} & \multicolumn{7}{|c|}{ Fuel oil consumption (Metric tons) } \\
\hline & & & & DO/GO & LFO & HFO & LPG (P) & LPG (B) & LNG & Others \\
\hline 01/01/2019 & & 210 & $24: 00$ & 2 & 2 & 19 & 0 & 0 & 0 & 0 \\
\hline 02/01/2019 & & 209 & $24: 00$ & 2 & 0 & 18 & 0 & 0 & 0 & 0 \\
\hline 03/01/2019 & & 217 & $24: 00$ & 2 & 0 & 20 & 0 & 0 & 0 & 0 \\
\hline .............. & $\ldots \ldots$ & $\ldots \ldots$ & $\ldots \ldots$ & $\ldots \ldots$ & $\ldots \ldots$ & $\ldots \ldots$ & ...... & ....... & $\ldots \ldots$ & $\ldots \ldots$ \\
\hline ….......... & $\ldots \ldots$ & $\ldots \ldots$ & $\ldots \ldots$ & $\ldots \ldots$ & $\ldots \ldots$ & $\ldots \ldots$ & ...... & ....... & $\ldots \ldots$ & $\ldots \ldots$ \\
\hline …........... & $\ldots \ldots$ & $\ldots \ldots$ & ....... & ....... & ....... & ....... & ....... & ....... & ....... & $\ldots \ldots$. \\
\hline $31 / 12 / 2019$ & & 216 & $24: 00$ & 1 & 0 & 20 & 0 & 0 & 0 & 0 \\
\hline Annual total & & & & & & & & & & \\
\hline
\end{tabular}

\subsection{Method Using Flow Meters}

\subsubsection{Method Analysis}

This method determines the annual total amount of fuel oil consumption by measuring fuel oil flows on board by using flow meters. The fuel flow is often measured directly (by volume, velocity or mass) or indirectly by pressure. In principle, flow meters readings of marine energy equipment should be recorded daily and fuel consumption of the ship should be calculated daily. [14]

Therefore, as long as the sum of the daily readings of the ship's flow-meter is recorded, the total fuel consumption for the ship's annual year can be determined.
Annual fuel oil consumption $=\sum_{n=1}^{365}$ (Daily fuel oil consumption data measured by flow meters)

The method using flow meters is shown in Figure 5.

The Data collection Plan should set out information about the ship's flow meters and how the data will be collected and summarized and what alternative methods will be conducted in case of the breakdown of flow meters. According to its working principles, flow meters can be mainly categorized as Positive Displacement Flow-meter (PDF) and mass flow-meter. [15]

\section{5 daily fuel oil consumption data}

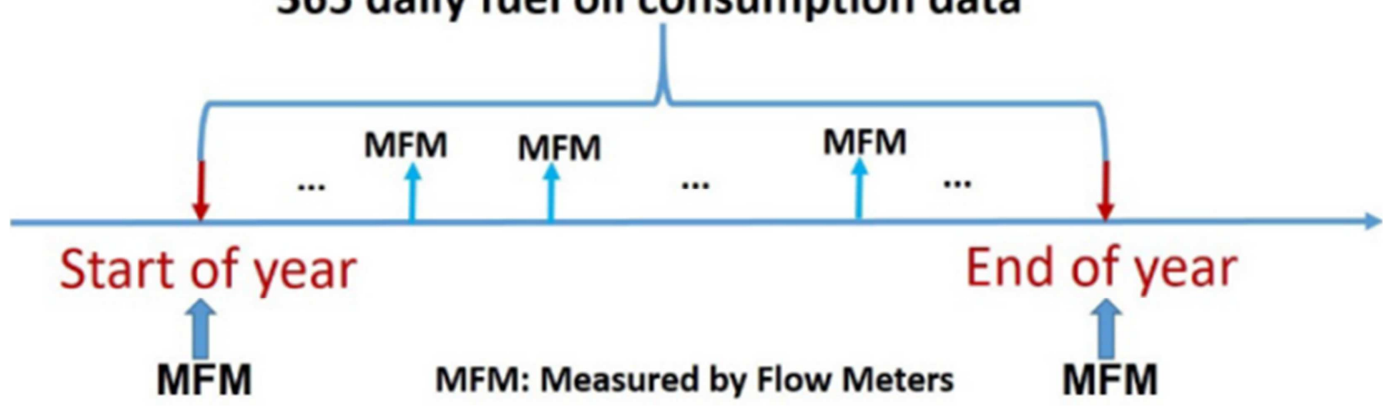

Figure 5. Method using flow meters.

\subsubsection{Precautions and Suggestions}

When using the flow-meter to measure the ship fuel consumption, the followings The following precautions and suggestions shall be noted:

1) If the flow-meter fails, manual tank reading or other alternative methods should be performed;

2) The connection of the flow-meter to specific fuel consumer should be described in the data collection plan;

3) Any fuel consumer not monitored by a flow-meter should be clearly identified and alternative fuel consumption measurement method shall be included;

4) If the flow-meter is installed after the fuel oil daily tank, there is no need to correct the fuel oil measurement method due to the sludge, because the sludge will be removed before the fuel reaches the fuel oil daily tank;

5) Calibration of flow meters shall be specified and records of calibration and maintenance shall be kept on board. 


\subsubsection{Data Format Submitted to Flag State by Ship}

When using flow meters to determine the total fuel oil consumption of the vessel for one calendar year, a summary of the data should be submitted to the flag state, and the format for reporting is the same as that by using bunker fuel oil tank monitoring on board, see table 5 .

\section{Practice and Precautions for Ship Fuel Consumption Data Collection and Reporting}

\subsection{Practice of Data Collection}

Sets of data related to ship fuel oil consumption have been successfully collected from 5 demonstration container ships. Each set of data includes 11 information fields: date and time, status, hours travelled, distance travelled, speed, fuel consumption of main engine, fuel type of main engine, fuel consumption of auxiliary engine, fuel type of auxiliary engine, fuel consumption of boiler and fuel type of boiler. [16] As the flow meters and their supportive electronic system are installed and working in normal conditions on 5 container ships, the data collected on these ships can be more frequent (every 15 minutes) and more accurate in an automatic manner compared to the manual daily data collected from oil tankers and bulk carrier. Based on all data collected, the annual fuel consumption data is able to be produced. This paper selected part of those fuel consumption data collected on a container ship for illustration. Figure 6 shows the example of part data collected on a container ship

\subsection{Aggregated Data}

Thus based on the annual data, the aggregated data table can be produced in accordance with regulation 22A and appendix IX of MARPOL Annex VI. Figure 7 shows the part of aggregated data table of the selected container ship.

\begin{tabular}{|c|c|c|c|c|c|c|c|c|c|c|c|}
\hline Date from & Date to & Distance Travelled (n.m) & Hours underway (hh:mm) & DO/GO & LFO & HFO & $L P G(P)$ & $\operatorname{LPG}(B)$ & LNG & Others & $\wedge$ \\
\hline 2018-12-03 & $2018-12-03$ & 195.86 & $12: 15$ & 0 & 0 & 33.78 & 0 & 0 & 0 & 0 & \\
\hline 2018-12-04 & 2018-12-04 & 16.77 & 2:15 & 0 & 0 & 5.98 & 0 & 0 & 0 & 0 & \\
\hline 2018-12-05 & 2018-12-05 & 196.25 & $12: 15$ & 0 & 0 & 34.11 & 0 & 0 & 0 & 0 & \\
\hline 2018-12-06 & 2018-12-06 & 202.42 & $12: 15$ & 0 & 0 & 43.29 & 0 & 0 & 0 & 0 & \\
\hline 2018-12-07 & $2018-12-07$ & 205.22 & $12: 15$ & 0 & 0 & 56.02 & 0 & 0 & 0 & 0 & \\
\hline $2018-12-08$ & $2018-12-08$ & 212.01 & $12: 15$ & 0 & 0 & 56.85 & 0 & 0 & 0 & 0 & \\
\hline 2018-12-09 & 2018-12-09 & 202.32 & $12: 15$ & 0 & 0 & 56.69 & 0 & 0 & 0 & 0 & \\
\hline $2018-12-10$ & $2018-12-10$ & 218.54 & $12: 15$ & 0 & 0 & 56.59 & 0 & 0 & 0 & 0 & \\
\hline 2018-12-11 & 2018-12-11 & 216.89 & $12: 15$ & 0 & 0 & 54.41 & 0 & 0 & 0 & 0 & \\
\hline $2018-12-12$ & $2018-12-12$ & 184.79 & $12: 15$ & 0 & 0 & 40.12 & 0 & 0 & 0 & 0 & \\
\hline $2018-12-13$ & $2018-12-13$ & 225.94 & $12: 15$ & 0 & 0 & 54.81 & 0 & 0 & 0 & 0 & \\
\hline 2018-12-14 & 2018-12-14 & 233.29 & $12: 15$ & 0 & 0 & 54.79 & 0 & 0 & 0 & 0 & \\
\hline $2018-12-15$ & 2018-12-15 & 215.25 & $12: 15$ & 0 & 0 & 54.52 & 0 & 0 & 0 & 0 & \\
\hline $2018-12-16$ & $2018-12-16$ & 194.44 & $12: 15$ & 0 & 0 & 40.44 & 0 & 0 & 0 & 0 & \\
\hline $2018-12-17$ & $2018-12-17$ & 198.99 & $12: 15$ & 0 & 0 & 43.06 & 0 & 0 & 0 & 0 & \\
\hline $2018-12-18$ & $2018-12-18$ & 4.13 & $0: 15$ & 0 & 0 & 2.69 & 0 & 0 & 0 & 0 & \\
\hline 2018-12-19 & 2018-12-19 & 133.99 & $12: 15$ & 0 & 0 & 102.85 & 0 & 0 & 0 & 0 & \\
\hline $2018-12-20$ & $2018-12-20$ & 5.90 & $8: 30$ & 0 & 0 & 12.16 & 0 & 0 & 0 & 0 & \\
\hline $2018-12-22$ & $2018-12-22$ & 141.57 & $8: 15$ & 0 & 0 & 68.10 & 0 & 0 & 0 & 0 & \\
\hline $2018-12-23$ & $2018-12-23$ & 17.80 & $1: 15$ & 0 & 0 & 6.93 & 0 & 0 & 0 & 0 & $=$ \\
\hline In total: & & 46411.65 & $3059: 45$ & 0 & 0 & 10054.87 & 0 & 0 & 0 & 0 & 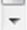 \\
\hline
\end{tabular}

Figure 6. Example of part data collected on a selected container ship.

\begin{tabular}{|c|c|c|}
\hline \multicolumn{3}{|l|}{ Identity of the ship: } \\
\hline & IMO Number: & 9345403 \\
\hline \multicolumn{3}{|c|}{ Period of calender year for which the data is submitted: } \\
\hline & Start date & 2018-04-01 \\
\hline & End date & $2018-12-23$ \\
\hline \multicolumn{3}{|c|}{ Technical characteristics of the ship } \\
\hline & Ship type: & Container ship \\
\hline & Gross Tonnage: & 114394 \\
\hline & Net Tonnage: & 54951 \\
\hline & Deadweight Tonnage: & 109968 \\
\hline & Main propulsion power(kW): & 68640 \\
\hline & Auxiliary engine power output (kW) & $4 * 3500(\mathrm{~kW})$ \\
\hline & EEDI: & N/A \\
\hline & Ice class: & N/A \\
\hline Fuel oil consumption: & & 10054.87 MT \\
\hline Fuel oil type: & & HFO \\
\hline Distance travelled: & & $46411.65 \mathrm{n}$ mile \\
\hline Hours underway: & & $46411: 38$ \\
\hline Method used: & & Method using flow meter \\
\hline
\end{tabular}

Figure 7. Part of aggregated data table of a container ship. 


\subsection{Precautions in Collecting Ship Fuel Consumption Data}

Based on the real practices and experiences of fuel consumption data collections on targeted ships, in addition to the precautions as raised in each methods in section 3 of this paper, there are some overall precautions that need to be taken when collecting and reporting ship fuel consumption data:

1) Whether the ship is underway or not, fuel consumption shall include all fuel consumers on board, and shall not be limited to the main engine, auxiliary engines, gas turbines, boilers and inert gas generators;

2) Within the same reporting period, the same method should be applied to collect data on ship fuel consumption. If it is really necessary to change the method, necessary records and explanations shall be made;

3) The daily fuel consumption data of ships should be recorded by electronic system in compliance with relevant requirements to avoid human errors and reduce the workload;

4) The ship's daily noon report can be designed to cover the fuel consumption data types, and thus fuel consumption data collection can be completed through the work of daily report without increasing the additional workload;

5) In order to verify the integrity, reliability and accuracy of the data, the flag state or the Recognized Organization may also require ships to provide copies of the ship's log book, engine log book, oil record book, BDNs, daily report, arrival and departure report, data collection plan, summaries of data, distance travelled and hours underway, information to demonstrate that the ship followed the data collection plan, etc.

\section{Conclusion}

The annual accurate amount of $\mathrm{CO}_{2}$ emissions from ships is one of the most important bases for the international shipping sector to scientifically develop the strategy of reducing the GHG emissions from ships, assess the implementation effectiveness of current mandatory regulations and introduce new mandatory regulations. The amount of $\mathrm{CO}_{2}$ emission $=$ ship's fuel consumption $\times$ fuel emission factor.

In order to mandatorily implement the ship fuel consumption data collection and reporting scheme, IMO adopted amendments to MARPOL Annex VI on data collection system for fuel oil consumption of ships through the resolution MEPC.278 (70), which entered into force on 1 March 2018. Under the amendments, the regulation 22A of collection and reporting of ship fuel oil consumption data, the Appendix IX on information to be submitted to the IMO Ship Fuel Oil Consumption Database and the Appendix X on Form of Statement of Compliance - Fuel Oil Consumption Reporting are added in the chapter 4 of MARPOL Annex VI.

However, to collect and report various fuel consumption data as regulated by the newly added regulation is never a easy process. Supported by "a pilot project of shipboard fuel consumption data collection", this paper systematically analyses the IMO requirements for ship fuel consumption data collections and data collection methods as discussed in section 2. Presently, there are three methods recognized by IMO for collecting fuel consumption data. When collecting ship fuel consumption data by using each, there might be various factors affecting the accuracy of the data, precautions and suggestions provided in this paper are advised to be taken into consideration so as to collect the data correctly and accurately.

And based on the shipboard real practices and experiences, the whole process of data collection is demonstrated, and precautions and suggestions for more accurate data collection are also provided, for the easy reference by parties concerned such as ship masters, ship owners, managers, maritime authorities, etc.

\section{References}

[1] Christos Gkerekos, Iraklis Lazakis, Gerasimos Theotokatos. Machine learning models for predicting ship main engine Fuel Oil Consumption: A comparative study [J]. Ocean Engineering 188 (2019) 106282.

[2] International Maritime Organization. Reduction Of GHG Emissions From Ships-Third IMO GHG Study 2014 [R]. [2014-07-01].

http://www.imo.org/en/OurWork/Environment/PollutionPreve ntion/AirPollution/Pages/Greenhouse-Gas-Studies-2014.aspx.

[3] Liu Zhaoqing. Ship fuel consumption reporting requirements of the MARPOL convention entered into force on 1 March, 2018 [J]. Navigation, 2018 (02): 48.(In Chinese)

[4] International Maritime Organization. Resolution MEPC. 278 (70)-Data collection system for fuel oil consumption of ships [EB/OL]. [2016-10-28]. http://www.imo.org/en/OurWork/Environment/PollutionPreve ntion/AirPollution/Pages/Data-Collection-System.aspx.

[5] Dongzhi MA, Xinping YAN, Jiangbin ZHAO, Tao ZHANG, "Remote Acquisition and Transmission System of Vessel Energy Efficiency Information," Journal of Transport Information and Safety, pp. 92-96, 2014.

[6] International Maritime Organization. 73/78 MARPOL convention consolidated edition 2018 [M]. London, IMO, 2018.

[7] Qi Xuetian. Discussion on the New Requirements of Ship Energy Efficiency Management Scheme and Fuel Consumption Data Collection System [J]. Marine Equipment/Materials \& Marketing, 2019 (03): 23-25. (In Chinese)

[8] International Maritime Organization. Resolution MEPC. 308 (73)-2018 Guidelines on the method of calculation of the attained EEDI for new ships [EB/OL]. [2018-10-26]. http://www.imo.org/en/About/Pages/DocumentsResources.asp $\mathrm{x}$.

[9] Ailong FAN, Qizhi YIN, Xinping YAN, Xing SUN, "Study of energy efficient navigation method for inland ship: A cruise ship case,'International Conference on Transportation Information and Safety IEEE, pp. 437-441, 2015. 
[10] International Maritime Organization. Resolution MEPC.282 (70)-2016 Guidelines for the development of a ship energy efficiency management plan (SEEMP) [EB/OL]. [2018-10-28]. http://www.imo.org/en/OurWork/Environment/PollutionPreve ntion/AirPollution/Documents/282(70).pdf.

[11] International Maritime Organization. Resolution A.1078 (28)-IMO Ship Identification Number Scheme. http://www.imo.org/en/About/Pages/DocumentsResources.asp $\mathrm{x}$.

[12] China Classification Society, CCS Guidelines for the development of ship energy efficiency management plan (SEEMP), 2013. (In Chinese).

[13] Moreno-Gutiérrez, J., Calderay, F., Saborido, N., Boile, M., Rodríguez Valero, R., Durán Grados, V., 2015. Methodologies for estimating shipping emissions and energy consumption: A comparative analysis of current methods [J]. Energy 86, 603616.

[14] Haakon Lindstad, Bjorn E. Asbjornslett, Anders H Stroman, "Reductions in green house gas emissions and cost by shipping at lower speeds", Energy Policy, vol. 39, no. 6, pp. 3456-3464, 2011.

[15] A Sala, F De Carlo, G Buglioni et al., "Energy performance evaluation of fishing vessels by fuel mass flow measuring system", Ocean Engineering, vol. 38, no. 5, pp. 804-809, 2011.

[16] Meng, Q., Du, Y., Wang, Y., 2016 Shipping log data based container ship fuel efficiency modeling [J]. Transp. Res. B 83, 207-229. 